\title{
Aproximações entre jornalismo e educação
}

Marina Lisboa Empinotti

Doutoranda em Estudos da Comunicação pela Fundação para a Ciência e a Tecnologia (FCT) alocada na Universidade da Beira Interior (UBI). Jornalista e mestra em Tecnologias,

Linguagens e Inovação em Jornalismo pelo Programa de Pós-graduação em Jornalismo (Posjor) da Universidade Federal de Santa Catarina (UFSC).

E-mail: marinaempinotti@gmail.com

Rita de Cássia Romeiro Paulino

Professora permanente do curso de Pós-graduação em Jornalismo (Posjor) e docente do curso de Jornalismo da Universidade Federal de Santa Catarina (UFSC).

E-mail: rita.paulino@ufsc.br

Resumo: Este artigo pretende evidenciar aproximações entre jornalismo e educação. Historicamente, são produtos consolidados com o advento do capitalismo. Epistemologicamente, confluem ao se enquadrarem ao âmbito cultural. Através de revisão bibliográfica, encontramos as semelhanças no desenvolvimento de ambos e chegamos a pesquisadores que defendem a função educadora como uma das responsabilidades do jornalismo nas sociedades contemporâneas. A educomunicação, possibilidade mais clara de unir os dois campos atualmente, será comentada, apesar de não ser o foco da reflexão. O jornalismo aqui abordado é aquele voltado à alimentação de mercado e à busca de lucro.

Palavras-chave: jornalismo; educação; mídia; sociedade da informação; responsabilidade social.
Abstract: This article presents similarities between Journalism and Education. Historically, they are products consolidated by the rise of capitalism. Epistemologically, they are framed in the cultural field. By making a deep bibliographical review, we can find similarities during the development of both areas and understand why there are contemporary authors that defend Education as one of Journalism's duties in contemporary societies. Edu-communication, a real possibility of bringing both areas together nowadays, is mentioned but not the focus of the study. The Journalism discussed is the one led by market demand.

Keywords: journalism; education; media; information society; social responsibility. 
comunicação \& educação • Ano XXIII • número 1 • jan/jun 2018

Malinowski entende que a cultura é uma totalidade que compreende processos técnicos, costumes, hábitos e valores herdados. Cada sociedade transmite às gerações seguintes o patrimônio cultural que recebeu de seus antepassados. MALINOWSKI, Bronislae. Uma teoria científica da cultura. Rio de Janeiro: Zahar, 1975

2. MELO, José Marques de; TOSTA, Sandra

Pereira. Mídia e educação. Belo Horizonte: Autêntica, 2008. (Coleção Temas \& Educação), p. 11.

3. Para Lyotard, contudo, na contemporaneidade não é mais o acesso à informação, mas como cada indivíduo se relaciona com ela. LYOTARD, Jean-François. $\mathrm{O}$ pós-moderno. 3. ed. Rio de Janeiro: José Olympio, 1988.

4. BOURDIEU, Pierre. What makes a social class? On the theoretical and practical existence of groups. Berkeley Journal of Sociology, Oakland, v. 32, p. 1-17, 1987

5. IJUIM, Jorge. Jornal escolar e vivências humanas: um roteiro de viagem. Covilhã: Livros LabCom, 2013, p. 27.

\section{INTRODUÇÃO}

O objetivo deste trabalho é analisar como as áreas do jornalismo e da educação evoluíram, separadamente, e evidenciar pontos que, para alguns autores, têm funções semelhantes nos dois campos, além da evidente perpetuação cultural ${ }^{1}$ promovida por ambos. Inclui-se, ao final da discussão, uma breve apresentação da educomunicação como possibilidade de união evidente das áreas. A escolha por não centrar a reflexão na educomunicação é baseada no fato de que o jornalismo aqui abordado é o voltado à alimentação de mercado e à busca de lucro; as práticas educomunicativas têm fins diferentes. Mesmo centrados no âmbito empresarial, pretendemos debater o papel de agente educativo atribuído ao jornalismo contemporâneo.

Sistema construído pelos meios de comunicação de massa, a mídia funciona em convergência histórica com a rede educativa, particularmente a escola, onde se concretiza a formação dos cidadãos, sob a égide do Estado. [...] Apesar de operarem segundo lógicas distintas, os dois sistemas estão em relação frequente, possuindo laços de dependência².

O educador Paulo Freire defendia uma pedagogia da pergunta, verbalizada ou não. Esse seria o início do processo da busca pelo conhecimento. Da mesma forma, começa o processo jornalístico: "O quê? Quem? Quando? Por quê?”. Nas sociedades contemporâneas, o acesso à informação é sinônimo de poder e nem sempre se dá de forma igualitária ${ }^{3}$. $\mathrm{O}$ acesso à informação não depende apenas dos meios disponíveis, mas da possibilidade de aceder a eles - não só em termos técnicos, mas em termos de "capital cultural", como defendia Bourdieu": a capacidade de interpretar, selecionar e utilizar a informação disponível.

A questão da responsabilidade social do jornalismo se releva aí. A imprensa tem papel histórico como tribuna para debates e instrumento de movimentos decisivos que culminaram em conquistas expressivas para a sociedade; agora pode ser um bom momento para a expansão de sua função educadora, discutida desde a Revolução Francesa. Veremos que, mesmo sem consenso quanto ao valor do conhecimento do jornalismo, embates semelhantes ocorrem no contexto pedagógico, no qual, até hoje, os conhecimentos "da certeza", validados por meio da experiência, são os que predominam no ambiente escolar.

A Educação tem por papel fundamental preservar e transmitir, de maneira crítica, o conhecimento historicamente acumulado. Mas essa maneira crítica supõe, no entanto, atitudes e valores que podem determinar como e com que finalidade esse conhecimento acumulado é trabalhado. E mais, decorre dessa criticidade a formação ampla desejada pelo sistema educacional. A falta de reflexão sobre tal questionamento, como reconhece o próprio MEC, proporciona à escola o grande risco de cumprir um papel apenas conservador ${ }^{5}$. 


\section{ABORDAGEM HISTÓRICA}

Apesar de considerados ambos filhos do capitalismo, tanto jornalismo como educação - nesse caso, materializada por meio do local criado especialmente para a transmissão de conhecimento, a escola - têm suas raízes na Idade Antiga, embora em sociedades distintas. A educação era muito valorizada na Grécia. Jorge Pedro Sousa ${ }^{6}$ considera as actas romanas como os primeiros jornais.

$\mathrm{O}$ autor português afirma que nenhum exemplar sobreviveu, mas os relatos sobre as actas são suficientes para embasar sua visão de que foram os primeiros produtos jornalísticos do mundo. Feitas por magistrados, escravos e funcionários públicos, chamados por Sousa de "primeiros jornalistas", desde o século II a.C., as actas eram copiadas, recopiadas e vendidas, como uma empresa jornalística atual.

As actas já eram divididas de acordo com o assunto abordado. Havia a acta senatus, sobre procedimentos administrativos e legislativos do senado; annalis pontificum, para o registro dos grandes acontecimentos da cidade; acta Populi; acta diurna etc. Muitas vezes eram diárias. Depois de circular, eram encadernadas e guardadas no arquivo do Estado, servindo também como registro histórico.

Podemos apontar uma série de semelhanças entre as actas diurnas e os jornais contemporâneos: periodicidade, frequência, conteúdo noticioso, corpo de escribas, difusão pública da informação, difusão quase massiva, diferentes suportes para a mesma mensagem - jornal de parede, jornal manuscrito, papiro -, iniciativa editorial do Estado e particulares etc. Um fato que merece destaque neste artigo é o de que as actas se tornaram possíveis na sociedade romana graças à infraestrutura de distribuição, como estradas e correios, mas, sobretudo, à alfabetização da elite, que poderia, então, consumi-las.

Entre os povos da Antiguidade, em matéria de educação, os gregos se sobressaem, com sua abordagem centrada na formação integral do indivíduo, em corpo e em espírito. O conhecimento passado variava de acordo com a cidade e o momento histórico, ora para o preparo militar ou esportivo, ora para o debate intelectual.

Existiam diversos locais da pólis que colaboravam na transmissão de conhecimento -algo ainda extremamente elitizado -, entre eles as próprias casas, seguindo tradições religiosas ou sob orientações de preceptores que ensinavam aos jovens. A incipiente escola era um lugar para a prática do "ócio digno", que significava, em uma sociedade escravagista, dispor de tempo livre, privilégio de quem não precisava cuidar do sustento. "Não é por acaso que a palavra grega para escola (scholé) significava inicialmente o lugar do ócio"7.

A historiografia grega, desenvolvida a partir do século V a.C., foi a primeira a ser elaborada com intenção de verdade, respeitando os fatos históricos e os separando de lendas, mitos e religião. Os registros dos fatos eram feitos nas efemérides (Ephaemeris), que eram disseminadas nas várias cidades-estado, cumprindo, simultaneamente, as funções de preservação dos fatos históricos e de difusão de notícias, da mesma maneira que ocorria com as actas romanas.
SOUSA, Jorge Pedro. Uma história breve do jornalismo no Ocidente. In: _ (org.). Jornalismo: história, teoria e metodologia. Porto: UFP, 2008, p. 12-92.

7. ARANHA, Maria Lucia. História da educação e da pedagogia: geral e Brasil. São Paulo: Moderna, 2006, p. 62 
8. SOUSA, Jorge Pedro. Tobias Peucer: progenitor da teoria do jornalismo. Estudos em Jornalismo e Mídia, Florianópolis, v. 1, n. 2, p. 31-47, jan. 2004, p. 32.

9. SOUSA, Jorge P. Tobias Peucer: progenitor da Teoria do Jornalismo. Estudos em Jornalismo e Mídia, Florianópolis, v. 1, n. 2, p. 31-47, jan. 2004

10. PEUCER, Tobias. Os relatos jornalísticos. Estudos em Jornalismo e Mídia, Florianópolis, v. 1, n. 2, p. 13-30, 2004.

11. Ibidem, p. 27.

12. Ibidem, p. 28.

13. SOUSA, Jorge Pedro, op. cit., 2008.

14. SOUSA, Jorge Pedro, op. cit., 2004.
Saltando para o século XVII, encontramos um período de criação de um espaço próprio para transmissão de conhecimento, a escola, e do "florescimento dos antepassados dos jornais contemporâneos" ${ }^{\text {. }} \mathrm{Na}$ época, o conhecimento, que até então era transmitido oralmente, tornou-se produto de uma instituição específica e de um conjunto de pessoas que se especializou na transmissão do saber. Tal cenário era composto pelos alunos, pertencentes às elites, e pelos professores, majoritariamente religiosos.

A imprensa era composta por diversos tipos de publicações. Havia as relações de novidades (relações de notícias), espécie de "compêndios noticiosos", e as folhas volantes, herdeiras diretas das folhas volantes manuscritas da Idade Média e dos avisos italianos e alemães, por exemplo. O crescimento e a variedade da imprensa foram bem-sucedidos não somente pelas possibilidades técnicas refinadas, como a prensa de Gutenberg e a expansão da indústria do papel, mas por fatores essencialmente sociais, como o desenvolvimento educacional trazido pela Reforma Protestante e a necessidade crescente por informação com a sociedade capitalista em expansão.

Esse cenário cheio de mudanças era o objeto das pesquisas de Tobias Peucer, definido por Sousa ${ }^{9}$ como um observador sagaz da diversificada imprensa informativa da época e que a elevou à condição de objeto de estudo, propondo uma primeira "teoria do jornalismo" em um tempo em que nem se falava de jornalismo, mas no qual, paradoxalmente, o campo começava a se consolidar.

Peucer $^{10}$, em sua tese de doutorado de 1690, reúne 29 parágrafos sobre suas observações da imprensa. Duas nos interessam aqui, já que tratam da relação entre a educação e o jornalismo. O autor fala, primeiramente, sobre a questão do letramento e, posteriormente, sobre conhecimento:

\section{XXVI}

Finalmente faz ver também outras utilidades para os letrados e para os iletrados, sobretudo para os comerciantes. Por tudo isso não há que acrescentar aí senão que, para se extrair estas utilidades, requer-se um conhecimento da geografia, dos negócios civis e sobretudo das coisas de palácio. Dado que isto são poucos os que tem a sorte de conseguir, é claro que estas utilidades não as podem explicar quem quer que seja ${ }^{11}$.

\section{XXVIII}

É ainda maior o prazer encontrado na leitura dos periódicos pelos eruditos: aqueles que gozam do conhecimento da geografia, da genealogia e dos afazeres cívicos. Porque todo relato é mais agradável se se conhece o local, as pessoas notáveis que foram autoras de um feito, ou as causas pelas quais se empenharam. Quem ignora que estas circunstâncias dos fatos sejam tiradas das partes do conhecimento mencionadas? ${ }^{12}$

Os jornais do século XVII mostram, para Sousa ${ }^{13}$, que a imprensa noticiosa não é uma invenção norte-americana do século XIX, mas sim uma invenção europeia de dois séculos anteriores, que "recupera uma tradição noticiosa (nunca perdida) iniciada com as efemérides gregas e as actas diurnas romanas"14. O período da Revolução Francesa (1789-1799) e os anos que a antecederam, 
por exemplo, foram "jornalisticamente efervescentes" 15 , com a imprensa política ganhando força diante da crise do absolutismo francês. A própria Declaração dos Direitos do Homem e do Cidadão continha ideias que afirmavam liberdades formais às publicações impressas, ainda que estas sofressem posteriores períodos de restrição, como o Napoleônico. "O jornalismo é filho legítimo da Revolução Francesa"16.

Surgem jornais com fins políticos, dirigidos por pessoas envolvidas na Revolução, em meio a uma imprensa predominantemente informativa. Também nessa época se sobressaem grandes nomes do jornalismo: Brissot, Hébert, Marat e Mirabeau são alguns exemplos. A Revolução dissemina novos ideais que marcam a prática jornalística do período: a transparência nos assuntos públicos, a imprensa como ator social central e o contato mais próximo com os leitores.

A função da imprensa na difusão das notícias e dos reflexos da Revolução não foi desprezada. Favorável ou hostil, muito depressa em liberdade estreitamente vigiada, ela ecoou os acontecimentos da França nas zonas anexadas - da Bélgica ao Reno, como mais tarde nas repúblicas irmãs -, foi o coração do dispositivo pedagógico da Revolução conquistadora. É, de fato, todo um dispositivo articulado que progressivamente se instaura, associando propaganda direta e indireta ${ }^{17}$.

O jornalismo nos Estados Unidos no século XIX, contudo, é importante para exemplificar a relação jornalismo-educação. A imigração favoreceu o aparecimento de uma imprensa de discurso mais simples e acessível às pessoas pouco alfabetizadas e às que dominavam mal o inglês, mas que desejavam se integrar à sociedade norte-americana. No dizer de García González ${ }^{18}$, o jornal se converteu no principal veículo de aprendizagem e de referência cultural para os imigrantes e provia-lhes informações políticas e econômicas que possibilitavam sua progressão social.

A partir de 1750, com a Revolução Industrial, tanto o jornalismo quanto a educação ganham força social. A população ascendia educacional e socialmente, segundo Jorge Pedro Sousa, já que a nova ordem precisava de pessoas com algum nível de instrução, o que também expandiu o Ensino Básico gratuito:

Crescentemente instruídos, com salários que, embora baixos, permitiam padrões de consumo e um nível de vida que o campo não dava, os operários, que entram em processo de "aburguesamento", vão ver na educação uma forma de progresso e ascensão social. Por outro lado, a instrução aumenta a capacidade de conhecer e ler o mundo, o que contribuirá para o aparecimento de uma imprensa destinada a responder às necessidades dos operários, muitos dos quais aburguesados ${ }^{19}$.

O fenômeno criou a necessidade de um número maior de pessoas que soubessem fazer coisas básicas como cálculos simples, ler e escrever, para ser mão de obra nas indústrias, operando máquinas. Outra demanda que nasceu nesse momento foi a disciplinarização dos estudantes, que precisavam ser obedientes à nova hierarquia que se formava. A escola, portanto, expandia seu papel na vida dos alunos.
15. SOUSA, Jorge Pedro, op. cit., 2008.

16. MARCONDES FILHO, Ciro. Dicionário da comunicação. São Paulo: Paulus, 2014.

17. VOVELLE, Michel. A Revolução Francesa e seu eco. Estudos Avançados, São Paulo, v. 3, n. 6, p. 25-45, 1989. Disponível em: <http://www.scielo.br/ scielo.php?script=sci_arttext\&pid=S0103-40141989 $000200003 \&$ lng $=e n \& n r-$ $\mathrm{m}=\mathrm{iso}>$. Acesso em: 4 set. 2017.

18. GONZÁLEZ, Gloria García. La conformación de la moderna prensa informativa (1848-1914). In: MOMPART, Josep Lluís Gómez; OTTO, Enric Marín (eds.). Historia del periodismo universal Madrid: Síntesis, 1999, p. 49-99.

19. SOUSA, Jorge Pedro, op. cit., 2004, p. 101. 
20. SOUSA, Jorge Pedro, op. cit., 2008, p. 139.

21. SCHUDSON, Michael. Discovering the news: a social history of American newspapers. New York: Basic Books, 1978.

22. HABERMAS, Jürgen. Historia y critica de la opinión pública. Barcelona: Gustavo Gili, 1981.

23. Educador, professor crítico, ensaísta e sociólogo brasileiro, expoente do movimento da Escola Nova. Participou intensamente do processo de formação da universidade brasileira

24. DALLABRIDA, Norberto. A Reforma Francisco Campos e a modernização nacionalizada do Ensino Secundário. Educação, Porto Alegre, v. 32, n. 2, p. 185-191, 2009.

25. BARBOSA, Marialva. Meios de comunicação e História: elos visíveis e invisíveis. In: CONGRESSO NACIONAL DE HISTÓRIA DA MÍDIA, 5., 2007, São Paulo. Anais.. São Paulo: Intercom Sociedade Brasileira de Estudos Interdisciplinares da Comunicação, 2007, p. 1-18.

26. Ibidem, p. 17.
Da mesma forma, o jornalismo vê suas funções crescerem com o cenário em transformação. A Revolução trouxe uma legislação liberal, a abolição de taxas, as inovações tecnológicas, a economia de mercado e urbanização. A ascensão da classe média urbana precisa ser destacada, já que gira em torno de alfabetização massiva, intervenção cívica, organização de partidos políticos, direito de voto e outros fatores estritamente ligados à educação.

Em 1841, Horace Greeley funda o The New York Tribune. Para Jorge Pedro Sousa, foi o primeiro jornal simultaneamente político e sensacionalista - seu fundador era também líder partidário -, bem como o primeiro a denunciar as "chagas profissionais profundas provocadas pela Revolução Industrial" ${ }^{20}$ : defendia a educação para todos, o combate ao desemprego, a generalização do emprego às mulheres e a todas as camadas sociais, a igualdade salarial para ambos os sexos, a abolição da escravatura e o fim do trabalho, entre outros.

A imprensa comercial de massas floresce, pois cai o consumo da imprensa de partido (party press) cara, parcial e elitista em uma sociedade agora democratizada. Ao longo da última metade do século XIX, uma imprensa predominantemente noticiosa, de discurso acessível, comercialmente agressiva e formalmente independente se impõe. Schudson ${ }^{21}$ afirma que essa imprensa "democratiza o mercado", ao mesmo tempo em que se democratiza a vida pública.

Como explica Habermas ${ }^{22}$, na imprensa comercial "de massas", o jornalista deixa de ser o juiz, passando essa função para o público. O papel dos jornais e dos jornalistas passa a ser o de providenciar informações para que o público possa analisar e julgar. O êxito desse sistema depende muito, evidentemente, da educação dos envolvidos.

No panorama brasileiro, cabe destacar a década de 1930, período no qual se inicia no país a chamada Segunda República (1930-1936), cujo presidente foi Getúlio Vargas. O Brasil entrava no mundo capitalista de produção e essa nova realidade exigia mão de obra mais bem qualificada, sendo, portanto, necessário investir na educação. Uma das ações mais importantes registradas foi o Manifesto dos Pioneiros da Educação Nova: propostas para a melhoria da educação nacional feitas por conceituados educadores da época, liderados pelo professor Fernando de Azevedo $^{23}$. Em 1930 foi criado o Ministério da Educação e Saúde Pública e, no ano seguinte, foi feita a Reforma Francisco Campos, que moldou os Ensinos Secundário e Superior no Brasil²4. Em 1934 foi publicada a nova Constituição, que pela primeira vez incluiu a educação como um direito de todos. Novas leis previam também o Ensino Primário gratuito em instituições públicas, com frequência obrigatória para os que estivessem em idade escolar.

Barbosa $^{25}$ destaca a centralidade do rádio como veículo de comunicação nessa época, de tal forma que os aspectos mais cotidianos da vida passam a ser regulados pela centralidade da mídia, tamanha a incorporação das mensagens e dos apelos midiáticos com relação ao público. "O que está em jogo é a produção de novas sociabilidades reguladas por estes aparatos tecnológicos que instauram relações dialógicas e produzem subjetividade" ${ }^{26}$. 


\section{ABORDAGEM EPISTEMOLÓGICA}

O ambiente escolar atual segue fortemente influenciado pelos paradigmas baseados na certeza e em concepções do século XVII. Ou seja, nele, o conhecimento válido é o científico, o que pode ser provado pela experiência. Descartam-se os outros tipos de conhecimento, como vivências pessoais dos alunos.

Essa discussão do âmbito educacional pode ser facilmente comparada às travadas no campo do jornalismo. Da mesma forma que muitos educadores defendem um ambiente escolar que valorize experiências de todos os tipos, existem questionamentos acerca da validade do jornalismo como conhecimento. Afinal, o que é conhecimento? É graças a paradigmas ainda não superados que há dúvidas desse tipo. A forma de pensar contemporânea segue fortemente influenciada pelos paradigmas baseados na certeza - medieval e mecanicista. Ijuim $^{27}$ sintetiza aspectos que ainda precisam ser superados (Quadro 1):

\section{Quadro 1: Características dos paradigmas medieval e mecanicista}

\begin{tabular}{|l|l|}
\hline Paradigma medieval & Paradigma mecanicista \\
\hline - Submissão & - Redução de toda realidade à soma das partes - \\
- Passividade & fragmentação, especialização, disciplinaridade \\
- Obediência & - Redução do real ao experimental - certeza, divisão \\
- Hierarquia rígida & sujeito-objeto \\
- Doutrina salvacionista - sofrer agora & - Homem e todos os seres vivos vistos como \\
para ser feliz depois, no paraíso & máquinas \\
& $\begin{array}{l}\text { - Primado da ciência, da experiência e da razão } \\
\text { - Ideia de homem dominador do planeta } \\
\text { - Individualismo } \\
\text { - Determinismo }\end{array}$ \\
\hline
\end{tabular}

Fonte: IJUIM, 2013.

Park $^{28}$ faz reflexões sobre a validade do jornalismo como conhecimento que podem ser expandidas para outras áreas. O autor reconhece dois tipos existentes de conhecimento: "conhecimento de" (conhecimento de trato) e “conhecimento acerca de". É importante destacar que as duas formas não são diferentes em caráter ou função; juntas constituem um contínuo.

$\mathrm{O}$ "conhecimento acerca de" é o validado desde a Idade Média: racional, formal, sistemático, baseado na observação e no fato verificado. O conhecimento científico divide-se em três: filosofia e lógica (interessa-se por ideias), história (interessa-se por acontecimentos) e ciências naturais ou de classificação (interessa-se por coisas).

O "conhecimento de" é o que adquirimos inevitavelmente a partir do contato com o mundo, através do uso e do hábito, não de investigação formal. Deixa-nos à vontade no mundo. Existem algumas formas de "conhecimento de": tato ou senso comum (informal e inconsciente), conhecimento clínico,

27. IJUIM, Jorge, op. cit. 28. PARK, Robert. A notícia como forma de conhecimento: um capítulo na sociologia do conhecimento. In: STEINBERG, Charles Side (org.). Meios de comunicação de massa. São Paulo: Cultrix, 1972, p. 168-185. 


\section{Ibidem.}

30. SANTOS, Boaventura de Sousa. Um discurso sobre as ciências. 2. ed. São Paulo: Cortez, 2004.

31. KAPLÚN, Gabriel. Kaplún, intelectual orgânico: memória afetiva. In: MELO, José Marques de et al. (orgs.). Educomídia, alavanca da cidadania: o legado utópico de Mario Kaplún. São Paulo: Unesco, Universidade Metodista de São Paulo, 2006, p. 37.

32. KAPLÚN, Mario. EI comunicador popular. 3. ed. Buenos Aires: Lumen-humanitas, 1996, p. 64.

33. RATIER, Rodrigo. David Buckingham fala sobre educação para as mídias. Nova Escola, São Paulo, 1 fev. 2001. Disponível em: <https://novaescola.org.br/conteudo/879/ david-buckingham-fala-sobre-educacao-para-as-midias>. Acesso em: 29 ago. 2017.

34. PARK, Robert, op. cit. conhecimento técnico ou habilidades e experimentação não dirigida - como o manejo de objetos.

Park $^{29}$ coloca ambos os tipos de conhecimento em um mesmo nível de credibilidade e valor social, embora isso não ocorra disseminadamente. Santos ${ }^{30}$ alerta para a urgência em se desvendar divisões que nos impossibilitem de ver as fronteiras em que a ciência moderna fragmentou a realidade.

Embora não seja o foco deste trabalho, é indispensável comentar a possibilidade mais clara de unir jornalismo e educação atualmente, a educomunicação. É uma alternativa ao cenário educacional atual, de redução da realidade à soma das partes: aprende-se biologia, matemática e física separadamente, sem a preocupação de saber integrá-las e aplicar o conhecimento adquirido. Isso leva a uma fragmentação indesejada. As práticas educomunicativas geram uma interdisciplinaridade interessante para o ambiente escolar. Permitem a integração do conhecimento - a ressaltar: conhecimento de todos os tipos, não apenas o científico - a favor de um bem comum, compartilhado por ambas as áreas: a conservação e a geração de cultura.

Mario Kaplún, pioneiro do campo, sempre buscou potencializar emissores capazes de interferir nos processos comunicativos, com papel de interlocutores, não somente de locutores entre os profissionais da comunicação, conforme destaca o filho do autor ${ }^{31}$. Mais do que pensar a comunicação educativa como um espaço específico, portanto, defendeu a necessidade de pensar o caráter educativo de todo o processo da comunicação. Kaplún lembra que comunicação deriva da raiz latina communis, "la misma raíz de comunidad, de comunión; expressa algo que se comparte: que se tiene o se vive em común" ${ }^{32}$.

Nos países mais urbanizados, o que inclui o Brasil, crianças e jovens passam mais tempo em contato com meios de comunicação - internet, televisão, rádio, revistas e videogames - do que na escola. O consumo de mídia na infância e adolescência só perde para o período de sono $^{33}$. Conhecendo a centralidade que a mídia ocupa na sociedade, a educomunicação propõe levar o jornalismo às escolas por duas vias distintas.

A primeira é ver os jovens como consumidores, interpretando criticamente as mensagens que recebem. A segunda é desafiá-los como produtores de mídia, para que usem as tecnologias disponíveis - o que vai desde uma folha de papel até gadgets sofisticados - para expressar seus pontos de vista. A meta é tornar os alunos conscientes sobre a atuação dos veículos de comunicação e usufruir dos recursos hoje possibilitados pelas tecnologias de informação e comunicação (TIC).

Incorporar práticas jornalísticas na escola é, portanto, agregar possibilidades naturais às crianças nas ações em torno da perpetuação cultural. Naturais por se tratar de meios de comunicação, presentes desde muito cedo na infância contemporânea, como meio não só de informação, mas de entretenimento. A proximidade entre diversão e informação pode ser uma chave para despertar interesse pela busca por conhecimento. 


\section{CONSIDERAÇÕES FINAIS}

Retomando os estudos de $\operatorname{Park}^{34}$, o jornalismo (o objeto da reflexão do norte-americano é a notícia) é situado no contínuo produzido entre as duas formas de conhecimento citadas anteriormente - "conhecimento de" (conhecimento de trato) e "conhecimento acerca de" -, ou seja, é um híbrido. Não tem conhecimento sistemático como as ciências. Parece a história por gostar de acontecimentos, mas não é, porque se refere a acontecimentos isolados, sem sequenciá-los como a história faz. Passado ou futuro só interessam ao repórter se projetam luz sobre o real e sobre o presente.

Validado como forma de conhecimento ou não, o jornalismo, do ponto de vista epistemológico, conflui com a educação, pois pertencem a um âmbito maior: o da cultura. Ijuim ${ }^{35}$ afirma que ambos, por meios, métodos e técnicas distintas, almejam contribuir com a conservação e geração de cultura, como também com interação entre culturas. A aproximação das áreas, seja educomunicativamente, propiciando à escola a apropriação de noções, posturas e técnicas do jornalismo que diversifiquem suas ações de conservação, geração e interação de culturas, seja com a livre circulação de produtos jornalísticos que levem conhecimento (aquele conhecimento próprio do jornalismo, híbrido entre o científico e o informal) às pessoas, precisa ser mais investigada.

Concretamente, muito pouco se sabe sobre os efeitos do Jornalismo sobre os indivíduos ou as sociedades. Existem várias hipóteses a este respeito, mas é muito difícil isolar as variáveis de forma a testá-las para fins de comprovação ${ }^{36}$.

Corroborando para destacar a importância de estudos desse tipo e para a relevância do jornalismo na sociedade contemporânea, Mar de Fontcuberta ${ }^{37}$ aponta as quatro dimensões do jornalismo do século XXI:

1. dimensão socializadora;

2. espaço para exercício de cidadania;

3. protagonista do ócio;

4. agente educativo.

Esta última é a que nos interessa aqui e define os meios de comunicação como possuidores de um tipo de saber que convive com o oferecido pelo sistema educacional. A sociedade contemporânea, midiática, depende dos meios para fazer circular grande parte do conhecimento produzido. Se a escola foi criada como espaço formal de educação, a ser complementada pelo ambiente familiar, hoje os meios de comunicação têm papel indispensável como terceiro elemento educativo.

35. IJUIM, Jorge, op. cit. 36. SAPERAS, Enric, 1987, apud MEDITSCH, Eduardo. O jornalismo é uma forma de conhecimento? Media e Jornalismo, Lisboa, ano 1, n. 1, p. 1-13, 2002, p. 11.

37. FONTCUBERTA, Mar de; BORRAT, Héctor. Periódicos: sistemas complejos, narradores en interacción. Buenos Aires: La Crujía, 2006. 
comunicação \& educação • Ano XXIII • número 1 • jan/jun 2018

\section{REFERÊNCIAS BIBLIOGRÁFICAS}

ARANHA, Maria Lucia. História da educação e da pedagogia: geral e Brasil. São Paulo: Moderna, 2006.

BARBOSA, Marialva. Meios de comunicação e História: elos visíveis e invisíveis. In: CONGRESSO NACIONAL DE HISTÓRIA DA MÍDIA, 5., 2007, São Paulo. Anais... São Paulo: Intercom - Sociedade Brasileira de Estudos Interdisciplinares da Comunicação, 2007. p. 1-18.

BOURDIEU, Pierre. What makes a social class? On the theoretical and practical existence of groups. Berkeley Journal of Sociology, Oakland, v. 32, p. 1-17, 1987.

DALLABRIDA, Norberto. A reforma Francisco Campos e a modernização nacionalizada do Ensino Secundário. Educação, Porto Alegre, v. 32, n. 2, p. 185-191, 2009.

FONTCUBERTA, Mar de; BORRAT, Héctor. Periódicos: sistemas complejos, narradores en interacción. Buenos Aires: La Crujía, 2006.

GONZÁLEZ, Gloria García. La conformación de la moderna prensa informativa (1848-1914). In: MOMPART, Josep Lluís Gómez; OTTO, Enric Marín. (eds.). Historia del periodismo universal. Madrid: Síntesis, 1999. p. 49-99.

HABERMAS, Jürgen. Historia y critica de la opinión pública. Barcelona: Gustavo Gili, 1981.

IJUIM, Jorge. Jornal escolar e vivências humanas: um roteiro de viagem. Covilhã: Livros LabCom, 2013.

KAPLÚN, Gabriel. Kaplún, intelectual orgânico: memória afetiva. In: MELO, José Marques de et al. (orgs). Educomídia, alavanca da cidadania: o legado utópico de Mario Kaplún. São Paulo: Cátedra Unesco; Universidade Metodista de São Paulo, 2006.

KAPLÚN, Mario. El comunicador popular. 3. ed. Buenos Aires: Lumenhumanitas, 1996.

LYOTARD, Jean-François. O pós-moderno. 3. ed. Rio de Janeiro: José Olympio, 1988.

MALINOWSKI, Bronislae. Uma teoria científica da cultura. Rio de Janeiro: Zahar, 1975.

MARCONDES FILHO, Ciro. Dicionário da comunicação. São Paulo: Paulus, 2014.

MEDITSCH, Eduardo. O jornalismo é uma forma de conhecimento? Media e Jornalismo, Lisboa, ano 1, n. 1, p. 1-13, 2002. 
MELO, José Marques de; TOSTA, Sandra Pereira. Mídia e educação. Belo Horizonte: Autêntica, 2008. (Coleção Temas \& Educação).

PARK, Robert. A notícia como forma de conhecimento: um capítulo na sociologia do conhecimento. In: STEINBERG, Charles Side (org.). Meios de comunicação de massa. São Paulo: Cultrix, 1972. p. 168-185.

PEUCER, Tobias. Os relatos jornalísticos. Estudos em jornalismo e mídia, Florianópolis, v. 1, n. 2, p. 13-30, 2004.

RATIER, Rodrigo. David Buckingham fala sobre educação para as mídias. Nova Escola, São Paulo, 1 fev. 2001. Disponível em: <https://novaescola.org. $\mathrm{br} /$ conteudo/879/david-buckingham-fala-sobre-educacao-para-as-midias $>$. Acesso em: 29 ago. 2017.

SANTOS, Boaventura de Sousa. Um discurso sobre as ciências. 2. ed. São Paulo: Cortez, 2004.

SCHUDSON, Michael. Discovering the news: a social history of American newspapers. New York: Basic Books, 1978.

SOUSA, Jorge Pedro. Tobias Peucer: progenitor da teoria do jornalismo. Estudos em Jornalismo e Mídia, Florianópolis, v. 1, n. 2, p. 31-47, jan. 2004.

. Uma história breve do jornalismo no Ocidente. In: (org.).

Jornalismo: história, teoria e metodologia. Porto: UFP, 2008. p. 12-92.

VOVELLE, Michel. A Revolução Francesa e seu eco. Estudos Avançados, São Paulo, v. 3, n. 6, p. 25-45, 1989. Disponível em: <http://www.scielo.br/ scielo.php?script=sci_arttext\&pid=S0103-40141989000200003\&lng=en\&nrm $=$ iso $>$. Acesso em: 4 set. 2017. 
